\title{
MATERIAIS COM MUDANÇA DE FASE: ANÁLISE DE DESEMPENHO ENERGÉTICO PARA O BRASIL
}

\section{PHASE CHANGE MATERIALS: ENERGETIC ANALYSIS FOR BRAZILIAN TERRITORY}

\author{
Vinícius Pons 1 \\ Universidade Federal do Paraná, Curitiba, PR, Brasil, vinicius@arqpons.com \\ George Stanescu ${ }^{2}$ \\ Universidade Federal do Paraná, Curitiba, PR, Brasil, stanescu@ufpr.br
}

\section{Resumo}

O potencial de redução do consumo de energia elétrica para manter o conforto térmico um uma sala comercial com área de $40 \mathrm{~m}^{2}$ foi avaliado para as oito zonas bioclimáticas definidas de acordo com a norma brasileira NBR 15.220-2005. Foi empregado na parede externa uma camada de material de mudança de fase (PCM) de origem orgânica natural. Foram consideradas três estratégias para a manutenção do conforto térmico: (1) uma bomba de calor funcionando conforme um ciclo de Carnot invertido com COP constante; (2) utilização da bomba de calor acima mencionada, mas priorizando sempre a ventilação com ar externo; (3) ventilação como no caso 2 e otimizando a bomba de calor da estratégia 1 . O controle do conforto térmico foi realizado somente para a manutenção na faixa $18^{\circ} \mathrm{C}-24^{\circ} \mathrm{C}$ da temperatura interna na sala, sendo o PCM de uma mistura de ácido cáprico e álcool dodecílico com temperatura de fusão de $26,5^{\circ}$ C. A estratégia 1 , permitiu uma redução de $4,28 \%$ no consumo de energia elétrica, para a cidade de Santa Maria no Rio Grande do Sul, enquanto com a estratégia 2 a redução foi de 13,33\%. Para Curitiba, foi possível reduzir 9,47\% do consumo de eletricidade ao utilizar a estratégia 2. Cálculos realizados com base na estratégia 3 para a mesma cidade indicam que o uso de PCM pode levar a uma redução de 20,18\% no consumo de energia elétrica. Os resultados numéricos com a estratégia 3 , indicam reduções de $90 \%$ do consumo de energia. Observou-se todos os casos estudados que a exergia solar tem o potencial de geração de energia suficiente para manter a temperatura interna na faixa de conforto. É clara a necessidade de avanço tecnológico para que esta transformação de exergia em energia elétrica aconteça sem tanta perda energética. Este trabalho qualificou estes dados de maneira a melhor entender a representatividade dos mesmos.

Palavras-chave: Eficiência energética. Conforto térmico. PCM. Materiais com mudança de fase.

\begin{abstract}
The potential of reducing electrical energy consumption to maintain thermal comfort in an office with an area of $40 \mathrm{~m}^{2}$ was evaluated for the eight bioclimatic zones defined according to the Brazilian norm NBR 15.220-2005. A layer of phase change material (PCM) of natural organic origin was employed on the outer wall. Three strategies for the thermal comfort maintenance were considered: (1) heat pump running according to an inverted Carnot cycle with constant coefficient of performance; (2) strategy 1 heat pump but always prioritizing the ventilation with external air when outside temperature is beneficial to indoor thermal control; (3) ventilation as in strategy 2 and maximum optimization of the heat pump used to maintain the temperature in the defined range. The temperature range $18^{\circ} \mathrm{C}-24^{\circ} \mathrm{C}$ was defined as thermal comfort and PCM was a mixture of capric acid and dodecyl alcohol with melting temperature of $26.5^{\circ} \mathrm{C}$. In strategy 1, PCM reduced $4.28 \%$ electrical energy consumption for Santa Maria, state of Rio Grande do Sul, while with strategy 2, the reduction was 13.33\%. For Curitiba, strategy 2 reduced 9.47\%. The results for strategy 3 for the same city shows that the use of PCM reduces $20.18 \%$ of electrical energy consumption. Simulation using the third strategy made possible a reduction around $90 \%$ of electrical energy. It was observed in all the cases studied that the solar exergy has the potential of generating enough energy to maintain the internal temperature in the range of comfort. It is clear the need for technological advancement so that this transformation of exergy into electrical energy happens without so much energy loss. This work has qualified these data in a way to better understand their representativeness.
\end{abstract}

Keywords: Energy efficiency. Thermal comfort. PCM. Phase change materials.

How to cite this article:

PONS, Vinicius; STANESCU, George. Materiais com mudança de fase: análise de desempenho energético para o Brasil. PARC Pesquisa em Arquitetura e Construção, Campinas, SP, v. 8, n. 2, p. 127-140, jun. 2017. ISSN 1980-6809. Disponível em:

<https://periodicos.sbu.unicamp.br/ojs/index.php/parc/article/view/8650228>. Acesso em: 15 dez. 2017.

doi:http://dx.doi.org/10.20396/parc.v8i2.8650228. 


\section{Introdução}

O desenvolvimento de todo o tipo de tecnologia, seja qual for a sua finalidade, hoje, diferentemente do que ocorria antes da crise do petróleo na década de 1970, deve ser analisado perante o seu comportamento com relação à energia, seja ela energia incorporada para produção, consumo de energia durante seu uso ou energia para descarte. O desempenho energético das construções vem sendo estudado sem descanso em todo o planeta. Novos métodos construtivos, elementos e materiais para a arquitetura que venham a surgir na academia ou mercado, devem ser estudados de maneira a evitar falsas impressões de eficiência. Não se pode afirmar que materiais utilizados no norte da Europa, por exemplo, para redução da perda de calor das edificações, terão o mesmo impacto sob o consumo energético de edificações no nordeste brasileiro no ponto de vista de manutenção do conforto térmico, haja vista a diferença climática das regiões.

No Brasil mais de $70 \%$ da produção energética tem origem em fontes renováveis. $\mathrm{O}$ abastecimento de construções representa $50,2 \%$ do total do consumo de energia do país (BRASIL, 2016).

As construções têm como objetivo criar um ambiente seguro das intempéries e acolhedor ao ser humano. $\mathrm{O}$ consenso atual dos métodos construtivos utilizados no Brasil nem sempre considera os efeitos da envoltória da edificação no ambiente construído interno e seu comportamento do ponto de vista térmico. Mesmo após a publicação das normas NBR 15.220 (ABNT, 2005) e NBR 15.575 (ABNT, 2013) não houve alteração notável no cenário da construção. Pesquisas que mostrem que a preocupação sobre materiais, técnicas construtivas, estratégias projetuais, que podem ajudar a alterar este panorama, são de grande importância para a sociedade.

Neste trabalho buscou-se trazer uma tecnologia que é conhecida desde a década de 1970, porém apenas nos últimos dez anos vem sendo aplicada e estudada com mais afinco para a construção civil. Os chamados materiais com mudança de fase, traduzido do inglês "Phase Change Materials" (PCM), vêm sendo estudados na bibliografia como uma opção de auxílio ao controle térmico interno das edificações. Os PCMs são materiais que armazenam grande quantidade de energia durante a troca de estado físico. Esta característica impacta em um aumento da inércia térmica da construção e, em alguns casos, pode ser favorável à redução do consumo de energia para manutenção do conforto térmico. Justamente, esta possível alteração do consumo energético é o objetivo desta pesquisa: estudar os máximos potenciais de redução do consumo de energia para manutenção do conforto térmico em edificações para as oito zonas bioclimáticas definidas na norma brasileira NBR 15.220 (ABNT, 2005). Buscouse responder à questão: qual o potencial, sob a ótica da redução do consumo de energia, da utilização de PCMs como camada de vedação externa de edificações, como alternativa às técnicas construtivas comumente utilizadas no Brasil (argamassa, alvenaria, argamassa)? Sabendo-se dos diferentes tipos de PCM disponíveis no mercado e estudados na bibliografia, escolheu-se o chamado BioBased PCM, material com mudança de fase com origem orgânica de fonte renovável devido à facilidade de acesso ao material no país estudado.

\section{Fundamentação}

PCMs, como camadas de paredes externas de edificações, vêm sendo testados em diversas pesquisas como materiais que possibilitam a redução da amplitude térmica no interior de edificações, o que significa menores picos de temperatura, sejam eles mínimos ou máximos, como na pesquisa de Silva et al (2012).

Os materiais foram classificados por Abhat (1983) em três grandes grupos baseados, por sua composição química: orgânicos (parafinas ou ácidos graxos), inorgânicos (sais hidratados) ou eutéticos, materiais híbridos entre os dois primeiros grupos. Tendo cada grupo características, pontos fortes e fracos. O mesmo autor apresenta alguns pontos importantes para o material, como baixo aumento de volume durante a troca de fase para evitar danos ao material que o armazena. O PCM deve sofrer total liquefação ou solidificação durante a troca de fase para evitar efeitos, como o chamado super-cooling que reduz a eficiência do material.

O PCM pode ser utilizado na construção civil de algumas maneiras. Pode-se utilizar via saturação de materiais, misturando-o à argamassa por exemplo. Utilização por microencapsulamento (Figura 1) ou macroencapsulamento (Figura 2).

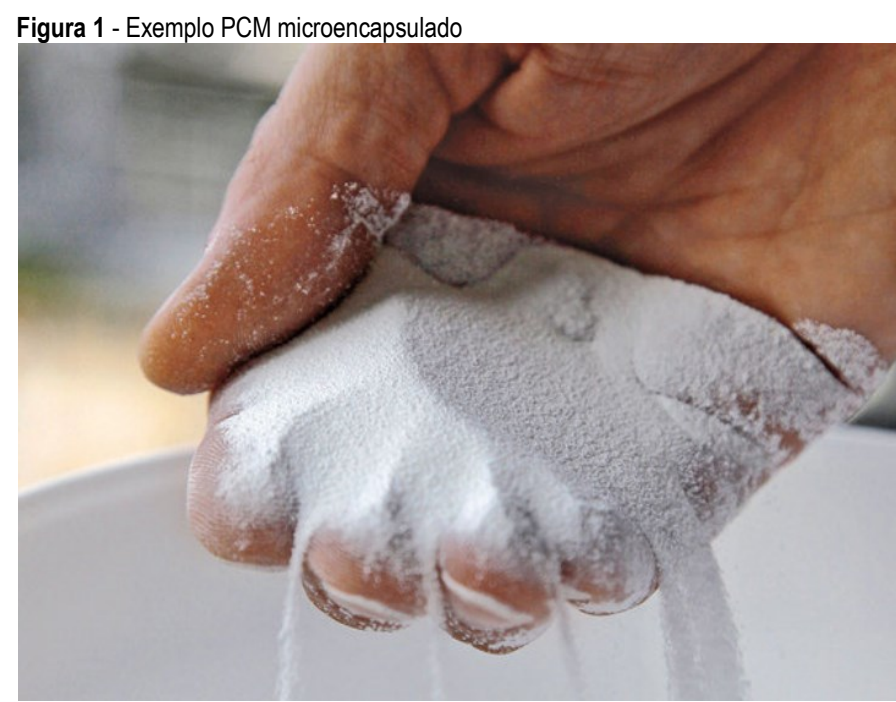

Fonte: (BASF, 2016). 
Cabeza et al. (2007) utilizaram o produto Micronal PCM (fabricante $\mathrm{BASF}^{1}$ ) com ponto de fusão a $26^{\circ} \mathrm{C}$ e entalpia de mudança de fase de $110 \mathrm{~kJ} / \mathrm{kg}$ misturados em uma placa de concreto de $0,12 \mathrm{~cm}$ de espessura. A pesquisa analisou experimentalmente o efeito da instalação destas placas em um cubículo construído para o estudo. Os resultados, para os meses de primavera e verão, mostraram uma redução efetiva da amplitude térmica interna. Halford e Boehm (2007) estudaram numericamente através da utilização do software MATLAB a influência da utilização de vedações do tipo "Isolante+PCM+Isolante" nos meses de primavera e verão. O PCM utilizado entre as camadas foi do tipo inorgânico, sal hidratado, e a pesquisa apresentou o quanto a mudança de fase do material influencia na transmissão de calor da camada externa para a camada interna da parede, gerando uma redução de $25 \%$ se comparado ao mesmo material sem a troca de fase.

Figura 2 - Exemplo PCM macroencapsulado

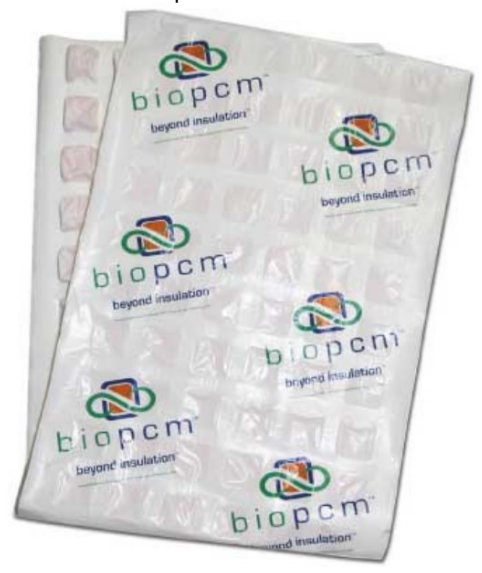

Fonte: (PHASE CHANGE ENERGY SOLUTIONS, 2016).

A utilização de PCM como no exemplo da pesquisa de Soares et al. (2014), tem sido testado sob diversas condições de aplicação e em diferentes localidades. A sua utilização na pesquisa reduziu em, no mínimo, $15 \%$ a carga de aquecimento ou resfriamento necessária para manutenção do conforto térmico interno (intervalo entre 20 e $25^{\circ} \mathrm{C}$ durante o horário comercial e 15 e $25^{\circ} \mathrm{C}$ no restante das horas) na totalidade anual do consumo.

A bibliografia apresenta resultados expressivos, como são os casos anteriormente descritos. Porém, nos cenários climáticos brasileiros os resultados serão os mesmos? A necessidade brasileira de um controle do consumo energético das edificações acompanha a tendência mundial. No Brasil as hidroelétricas representam mais de $50 \%$ de toda a geração energia, e apenas aproximadamente $11 \%$ do total são provenientes de outras fontes energéticas renováveis (BRASIL, 2016). A mesma bibliografia apresenta um crescimento de $65 \%$ do consumo energético do setor comercial nos últimos 10 anos. Um estudo da Eletrobras/Procel (ELETROBRAS, 2009) quantifica em, aproximadamente, $48 \%$ o gasto de energia elétrica do setor comercial para ar condicionados. Pereira, Lamberts e Ghisi (2013) apresentam o Brasil na quinta colocação do ranking de compra de sistemas de condicionamento de ar.

Bodach e Hamhaber (2010), estudaram uma edificação na cidade do Rio de Janeiro, na qual evidenciaram a importância de uma análise cuidadosa do impacto do projeto sobre o conforto térmico do ambiente construído. Os autores analisaram habitações sociais quanto às possibilidades de melhorias e os impactos financeiros dessas alterações. Uma das sugestões apresentadas na pesquisa é a do uso de materiais que permitam um maior controle da temperatura interna e seus impactos na temperatura interna da edificação. Os autores afirmam ainda os resultados benéficos dessas ações no crescimento do consumo energético brasileiro.

Kalnæs e Jelle (2015) apresentam em seu trabalho a possibilidade, trazida pelo material com mudança de fase, de uma utilização mais dinâmica da energia por parte da edificação, ou seja, o material absorve energia durante o dia, quando a mesma pode ser em excesso, e a libera à noite para amenizar as baixas temperaturas diárias.

Cabeza et al. (2007), Mandilaras et al. (2013) e Lee et al. (2015) realizaram testes experimentais na Espanha, Grécia e Estados Unidos, respectivamente, e obtiveram resultados satisfatórios em relação à redução do consumo de energia para manutenção do conforto térmico interno dos cubículos ou edificações estudadas.

Halford e Boehm (2007), Sajjadian, Lewis e Sharples (2015), Wang e Zhao (2015), Silva et al. (2012), Izquierdo-barrientos et al. (2012), De Gracia et al. (2015), Huang, Eames e Norton (2004), Fiorito (2014), Kosny et al. (2012) e Soares et al. (2014), apresentaram estudos de simulação energética para várias cidades de diferentes países e através de diversos métodos e softwares de cálculo, como MATLAB e EnergyPlus (sendo este o mais utilizado), buscando entender o comportamento de edificações em relação ao consumo de energia elétrica para manutenção do conforto térmico.

Kong et al. (2013) utilizaram uma mistura dos materiais com mudança de fase orgânicos, ácido cáprico e ácido dodecílico, provenientes de origem animal e vegetal, respectivamente. Os autores avaliaram o material de maneira macroencapsulada em placas de alumínio de $40 \times 40 \mathrm{~cm}$ (Figura 3) como uma camada do envelope de cubículos na China. Os resultados obtidos apresentaram temperaturas sempre entre 1 e $2^{\circ} \mathrm{C}$ abaixo do modelo de referência e um atraso de transmissão de calor de até 3 horas. 


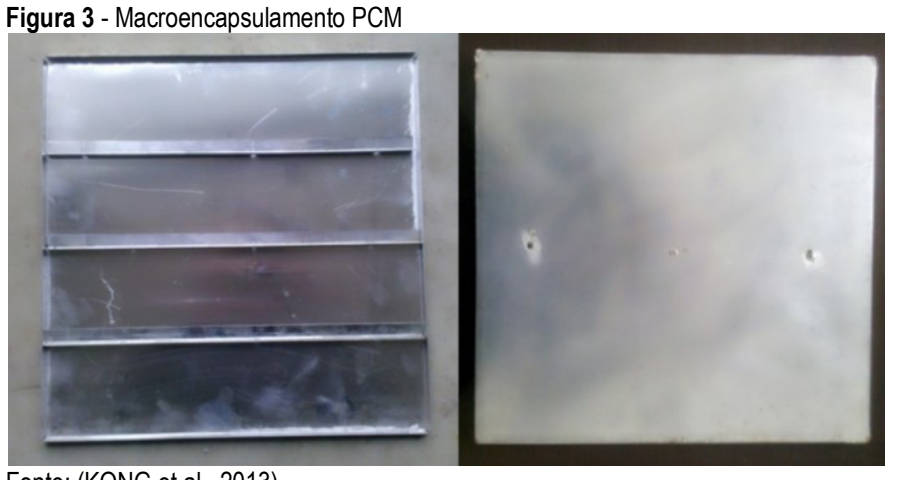

Fonte: (KONG et al., 2013).

\section{Método}

Ao escolher a modelagem numérica para análise do desempenho energético, definiu-se que a presente pesquisa se trata de um experimento, pois serão alteradas algumas variáveis e mantidas outras conforme sugerido por Robson (2002). Pelo mesmo autor, trata-se de uma pesquisa fixa, por obter resultados quantitativos.

Neste trabalho, serão apresentados o potencial de redução do consumo de energia para um escritório comercial com operação diurna em um edifício com estrutura de concreto armado e envoltória em alvenaria, locado em oito cidades de diferentes regiões do Brasil, sob o impacto da utilização do material com mudança de fase especificado (composto de ácido cáprico e álcool dodecílico) na parede externa do modelo físico definido. Para cada sistema simulado será calculada também a exergia solar recebida pelo modelo físico, e analisada em contraponto à exergia total recebida pelo mesmo (exergia solar somada à energia elétrica necessária para manutenção do conforto térmico interno). Quantificar a fração de exergia solar quando comparada à total, significa demonstrar o potencial de energia disponível e desperdiçada para os casos simulados, objetivando assim introduzir uma nova dimensão às análises de eficiência energética.

As análises foram baseadas em propriedades dos PCMs apresentadas na pesquisa de Kong et al. (2013). As propriedades de todos os materiais e elementos pertinentes ao modelo físico constam na NBR 15.220 (ABNT, 2005). Este trabalho não teve como foco o desenvolvimento de parâmetros para o material estudado, apenas procurou-se entender o comportamento térmico das edificações quando da utilização do mesmo.

A pesquisa teve início com a busca pelo referencial teórico necessário para compreensão do estudo. Continuada então pelo desenvolvimento do algoritmo computacional (na linguagem Fortran) para realização dos cálculos do método numérico, de maneira que representasse de maneira satisfatória o comportamento notado na realidade. Estabeleceu-se o modelo físico que seria utilizado para todas as cidades a serem simuladas. Houve, então, a definição do intervalo de conforto térmico para a pesquisa em questão. Os casos a serem calculados foram então determinados para, em seguida, serem rodadas as simulações e analisados os resultados.

A análise do conforto térmico e de possíveis estratégias de atuação para sua manutenção é frequentemente explicada através de cartas psicrométricas. Na carta psicrométrica da cidade de Curitiba (Figura 4) os pontos azuis representam as temperaturas máximas e mínimas, e os pontos na cor laranja as temperaturas médias para todos os dias do ano, cada um com dados de temperatura de bulbo seco e umidade relativa. Também é apresentada uma faixa na cor verde que representa o intervalo de conforto térmico. Nota-se, levando em consideração a temperatura, que apenas uma pequena parte das médias diárias encontra-se nesta área. Ou seja, é clara a necessidade de ação, seja por métodos passivos ou ativos, para a manutenção do conforto térmico internamente.

Figura 4 - Carta psicrométrica para Curitiba, Brasil

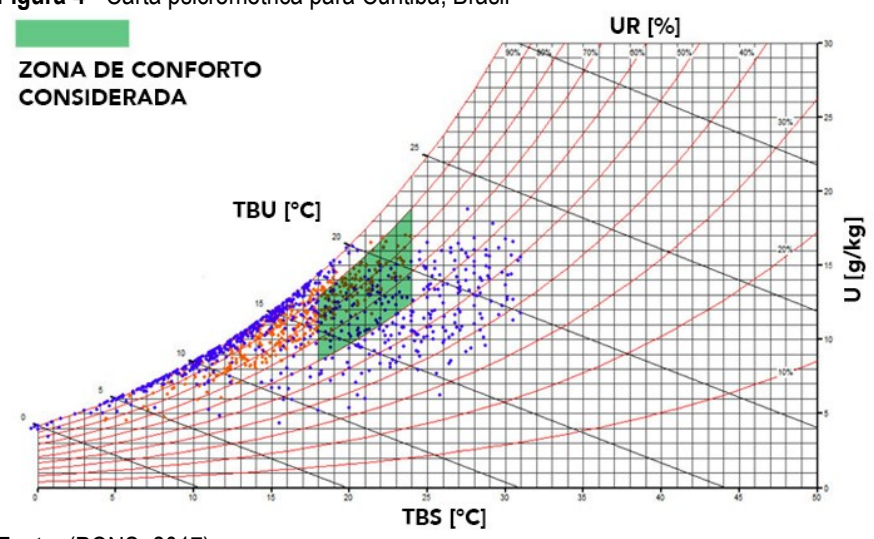

Fonte: (PONS, 2017).

De maneira a simplificar o modelo, e considerando que este trabalho não tem como foco o aprofundamento sob as teorias de conforto térmico, utilizaram-se os valores de $18^{\circ}$ $\mathrm{C}$ como valor mínimo e $24^{\circ} \mathrm{C}$ como máximo da faixa de conforto térmico em comum acordo entre os autores. Os valores, apesar de não seguirem normas como a ASHRAE 55 (2013), está próximo ao utilizado pela bibliografia da área como Sajjadian, Lewis e Sharples (2015) e Izquierdobarrientos et al. (2012). A umidade interna não foi controlada neste algoritmo; apesar de ser calculada hora a hora no volume de controle, apenas a faixa de temperatura foi mantida durante as simulações.

Este trabalho discutirá não somente valores de consumo de energia economizados mês a mês $(\mathrm{kWh})$, mas também potenciais de redução através de novos entendimentos da ação dos materiais e equipamentos em função do ambiente construído. Também discutirá os desperdícios energéticos (em outras palavras entropia) se considerado o sol como fonte de energia através da exergia solar. 
Como modelo físico de uma única zona, foi considerada uma sala comercial no $25^{\circ}$ andar de um edifício. A sala possui medidas de 8 (oito) metros de largura por 5 (cinco) metros de profundidade, com 3 metros de altura interna, perfazendo assim uma área de $40 \mathrm{~m}^{2}$ e um volume de 120 $\mathrm{m}^{3}$. Na parede externa existe uma janela de vidro transparente de $7 \mathrm{~m}^{2}$. Os acabamentos internos foram considerados pintura em branco com o piso assoalho de madeira. (Figura 5)

Exceto a face para o exterior, parede norte, todas as outras faces do modelo foram consideradas com uma superfície adiabática em seu eixo.

Para definição da geração de calor interna, um escritório similar existente na cidade de Curitiba, Paraná, foi utilizado para obtenção dos dados (Tabela 1), assim como a quantidade de mobília para inserção no modelo de cálculo.

Figura 5 - Planta modelo físico

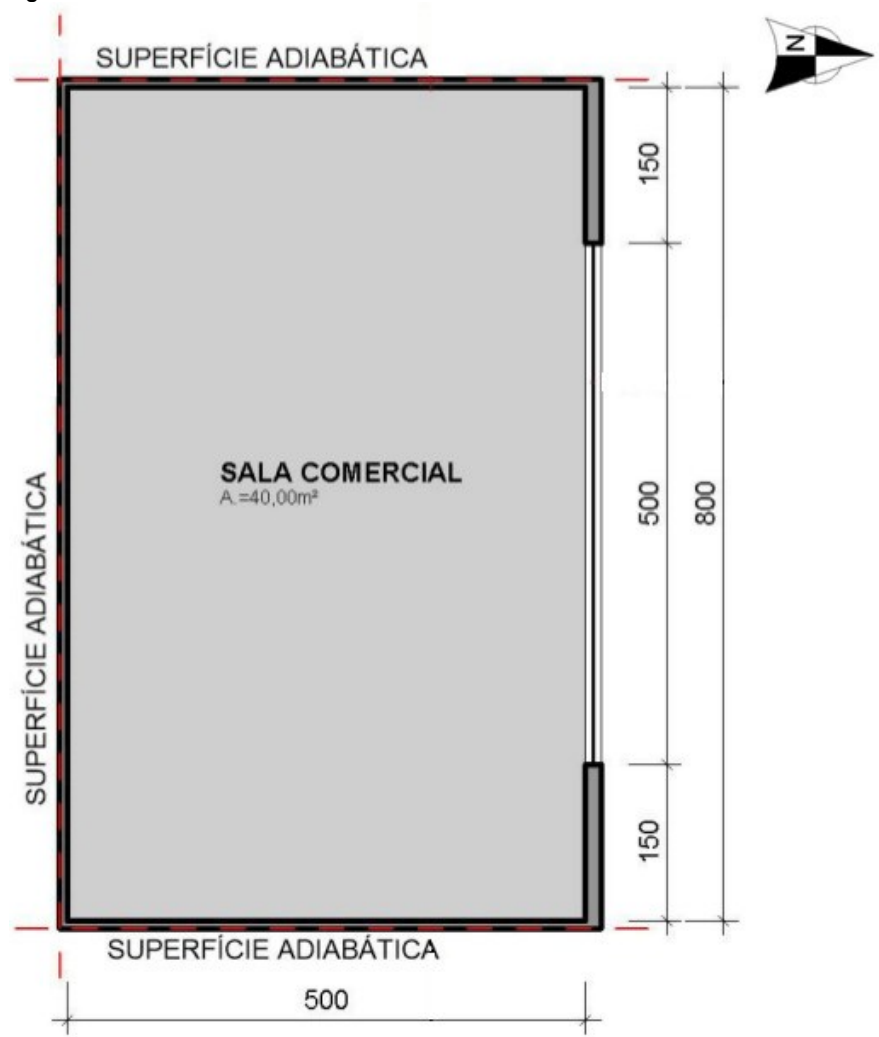

Fonte: (PONS, 2017).

\begin{tabular}{ccc}
\multicolumn{3}{l}{ Tabela 1 - Descrição geração de energia interna } \\
\hline Quantidade & Descrição & Potência \\
\hline 04 & Pessoas & $80 \mathrm{~W}$ \\
\hline 04 & Computadores e Monitores & $50 \mathrm{~W}$ \\
\hline 02 & Impressora & $2 \mathrm{~W}$ \\
\hline 01 & Iluminação & $50 \mathrm{~W}$ \\
\hline
\end{tabular}

Fonte: (PONS, 2017)

Como o modelo físico é um escritório comercial é importante delimitar o horário de funcionamento, haja visto que as cargas internas serão geradas apenas dentro deste horário. Foram considerados três tipos de dias padrão: dia de semana (entre segunda-feira e sexta-feira), sábado e domingo ou feriado. Nos dias de semana foi considerado horário de funcionamento das 9:00 às 18:00 h. Para o sábado das 9:00 às 14:00 h. Domingos e feriados não há expediente. Como feriados, foram definidos apenas os nacionais.

A ventilação para o ambiente definido foi considerada constante; o algoritmo considera ventilação sempre que existam pessoas no volume de controle. Foi adotado o valor de $0,9 \mathrm{l} / \mathrm{s} / \mathrm{m}^{2}$ conforme norma de condicionamento de ar e qualidade do ar interno, NBR 16401 (ABNT, 2008).

O modelo físico contém quatro paredes (norte, sul, leste e oeste), um forro e um piso. As paredes sul, leste e oeste são definidas de dentro para fora com uma camada de argamassa de 2,5 $\mathrm{cm}$ de espessura e uma camada de tijolo maciço de $5 \mathrm{~cm}$. O forro é formado por duas camadas, argamassa de 2,5 cm de espessura e laje mista de $5 \mathrm{~cm}$. O piso internamente é assoalho de madeira de $2 \mathrm{~cm}$, e laje mista na face exterior de $5 \mathrm{~cm}$. A parede externa (norte) do modelo referencial é composta de três camadas, sendo argamassa de $2,5 \mathrm{~cm}$ de espessura externamente, uma camada interna de $10 \mathrm{~cm}$ de tijolo maciço e outra $2,5 \mathrm{~cm}$ de argamassa pelo outro lado. Para a janela existente na parede norte foi considerado vidro de $6 \mathrm{~mm}$ de espessura.

Os dados dos materiais do modelo de referência para este estudo foram retirados da norma NBR 15.220 (ABNT, 2005). Para os materiais que continham uma faixa de valores na citada norma, utilizou-se a média de tal faixa para entrada no algoritmo de cálculo desta pesquisa.

Para esta pesquisa foi escolhido um PCM do tipo orgânico bio-based (com fonte biológica e renovável). Os PCMs de fontes biológicas são aglomerados de ácidos graxos feitos de matéria-prima subutilizada de óleo de soja, óleo de coco, azeite de dendê (palm oils) e sebo bovino. Se comparados às parafinas (também PCM orgânico) são significantemente menos inflamáveis e é esperado que se mantenham estabilizados por milhares de ciclos de mudança de fase, sem risco de oxidação. Estes materiais podem ter ponto de fusão entre $-22,7^{\circ} \mathrm{C}$ e $78,33^{\circ} \mathrm{C}$, o que possibilita aplicação em diversas áreas e regiões climáticas (JEONG et al., 2013 e KOSNY et al., 2012).

O material escolhido aparece na pesquisa de Kong et al. (2013) e trata-se de uma mistura de dois compostos de fontes renováveis, o ácido cáprico e o álcool dodecílico, o primeiro de origem animal e o segundo vegetal. A mistura dos dois compostos foi proposta pelos pesquisadores para conter o efeito de supercooling e para ajustar a temperatura de fusão/solidificação. O composto final foi analisado em um DSC (differential scanning calorimetry) de maneira a 
analisar e levantar suas propriedades de transferência de calor (Tabela 2).

Tabela 2 - Propriedades do material com mudança de fase

\begin{tabular}{cc}
\hline PCM - Ácido Cáprico e Álcool Dodecílico \\
\hline Condutividade Térmica [W/(m.K)] - Sólido & 0,12 \\
\hline Condutividade Térmica $[\mathrm{W} /(\mathrm{m} . \mathrm{K})]$ - Líquido & 0,20 \\
\hline Densidade $\left[\mathrm{kg} / \mathrm{m}^{3}\right]$ - Sólido & 784 \\
\hline Densidade $\left[\mathrm{kg} / \mathrm{m}^{3}\right]$ - Líquido & 817 \\
\hline Calor Específico $[\mathrm{J} /(\mathrm{kg} . \mathrm{K})]$ - Sólido & 1890 \\
\hline Calor Específico [J/(kg.K)] - Líquido & 2080 \\
\hline Entalpia de Fusão [J/kg] & 126900 \\
\hline Temperatura de Fusão $\left[{ }^{\circ} \mathrm{C}\right]$ & $26,5^{\circ} \mathrm{C}$ \\
\hline
\end{tabular}

Fonte: (PONS, 2017).

O PCM foi utilizado como a camada mais interna da parede norte do modelo físico. A espessura foi determinada durante as etapas de simulação de maneira a otimizar a utilização do seu potencial de liquefação, utilizando assim toda a energia de entalpia disponível.

A partir do modelo físico de referência, duas variáveis foram alteradas: espessura da camada com PCM e a cidade no qual o modelo foi simulado. Dois casos foram definidos por cidade: Caso 1 (referência) - sem camada PCM; Caso 2 - com camada PCM.

A dimensão do território brasileiro gera diversas diferenças climáticas. Existem cidades com maior amplitude térmica, mais e menos úmidas, com maiores picos de temperaturas e também com picos negativos, como é o caso da região serrana de Santa Catarina e Rio Grande do Sul. Estes diferentes cenários não permitem uma conclusão prévia da adequação ou não de uma ou outra estratégia projetual para otimizar o conforto térmico interno. Há de fato a necessidade de estudo para cada uma destas "regiões climáticas". No Brasil a NBR 15.220 (ABNT, 2005) definiu oito zonas bioclimáticas para toda a extensão do território, sugerindo estratégias de projeto para as edificações em cada uma destas zonas. Este trabalho então, utilizará os dados de uma cidade por zona bioclimática, para a simulação do modelo físico (Quadro $1)$.

Quadro 1 - Definições de cidade por zona bioclimática
\begin{tabular}{|c|c|}
\hline ZONA BIOCLIMÁTICA & CIDADE \\
\hline ZONA 1 & Curitiba, Paraná \\
\hline ZONA 2 & Santa Maria, Rio Grande do Sul \\
\hline ZONA 3 & São Paulo, São Paulo \\
\hline ZONA 4 & Brasília, Distrito Federal \\
\hline ZONA 5 & Vitória da Conquista, Bahia \\
\hline ZONA 6 & Campo Grande, Mato Grosso do Sul \\
\hline ZONA 7 & Cuiabá, Mato Grosso \\
\hline ZONA 8 & Rio de Janeiro, Rio de Janeiro \\
\hline
\end{tabular}

Fonte: (PONS, 2017).

Foram utilizados os arquivos de dados climáticos disponibilizados no site do software Energyplus (U.S. DEPARTMENT OF ENERGY, 2016) e pelo trabalho de
Roriz (2012) junto ao grupo de trabalho sobre Conforto e Eficiência Energética em Edificações da ANTAC Associação Nacional de Tecnologia do Ambiente Construído.

O modelo matemático utilizado para as simulações deste trabalho baseia-se nas leis de conservação de massa de ar seco e vapor d'água, e na lei de conservação da energia num volume de controle representado a sala comercial. $\mathrm{O}$ volume de controle representa apenas o ar interno sala em questão, com as paredes utilizadas para consideração da transferência de calor e inércia térmica do modelo físico.

O modelo utilizado considera que todos os pontos da massa de ar interna têm a mesma temperatura e umidade relativa (modelo well stirred tank). É importante salientar que não há, no modelo, variação de pressão, mantendo-se sempre estável durante todo o cálculo. Também não há troca de massa entre as paredes, piso e teto. A massa de ar seco e o vapor d'água foram considerados gases perfeitos, e a transferência de calor se dá apenas perpendicularmente às faces das paredes (Figura 6).

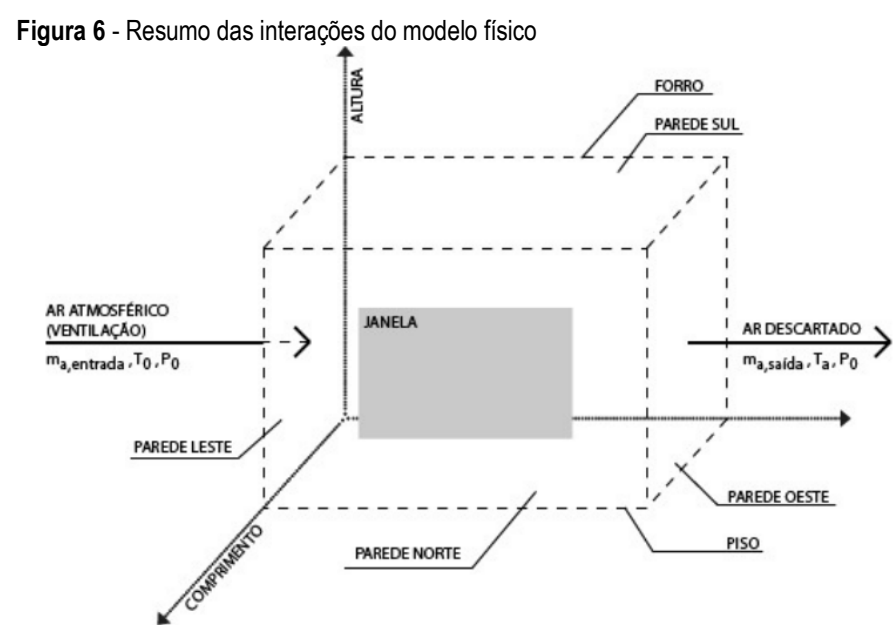

Fonte: (PONS, 2017).

Este modelo foi escrito em linguagem Fortran, dando continuidade ao trabalho já realizado por Stanescu e Schmid (2014).

O algoritmo desenvolvido calcula primeiramente as energias térmicas necessárias para manutenção da temperatura de conforto interna da edificação simulada. Em seguida, são utilizadas três estratégias de cálculo do consumo estimado de energia elétrica:

Estratégia 1 - Geração de energia através da utilização de equipamentos de aquecimento ou resfriamento, bomba de calor e refrigeração, baseado em um ciclo Carnot invertido (Figura 7).

Estratégia 2 - O uso da ventilação forçada como fator ativo do controle térmico pode gerar resultados de redução de consumo significativos. Neste trabalho, utilizou-se a 
ventilação como uma otimização do sistema original. A Figura 8 apresenta duas possibilidades de utilização da diferença de temperatura entre o ar externo e interno do volume de controle. Quando $\mathrm{T}_{0}>\mathrm{T}_{\text {int }}$ e há a necessidade de aquecimento, prioriza-se a utilização do ar externo para aquecimento. Quanto $\mathrm{T}_{0}<\mathrm{T}_{\text {int, }}$ havendo necessidade de resfriamento também é acionada a ventilação. A diferença de temperaturas interna e externa não sendo favorável à manutenção do conforto térmico interno, é utilizado então o equipamento da estratégia 1.

Figura 7 - Estratégia 1 de cálculo do consumo energético para manutenção do conforto térmico no volume de controle

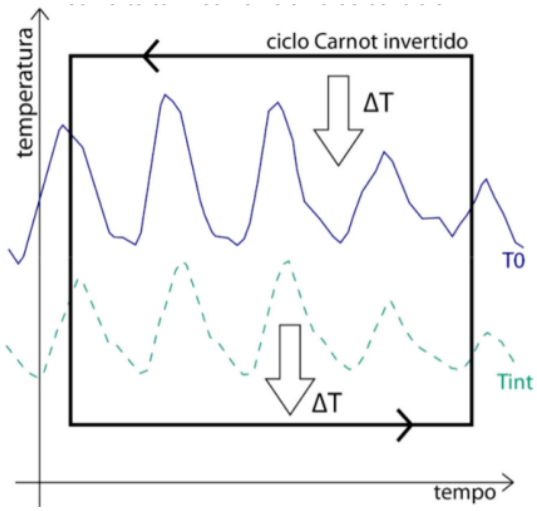

Fonte: (PONS, 2017).

Figura 8 - Estratégia 2 de cálculo do consumo energético para manutenção do conforto térmico no volume de controle
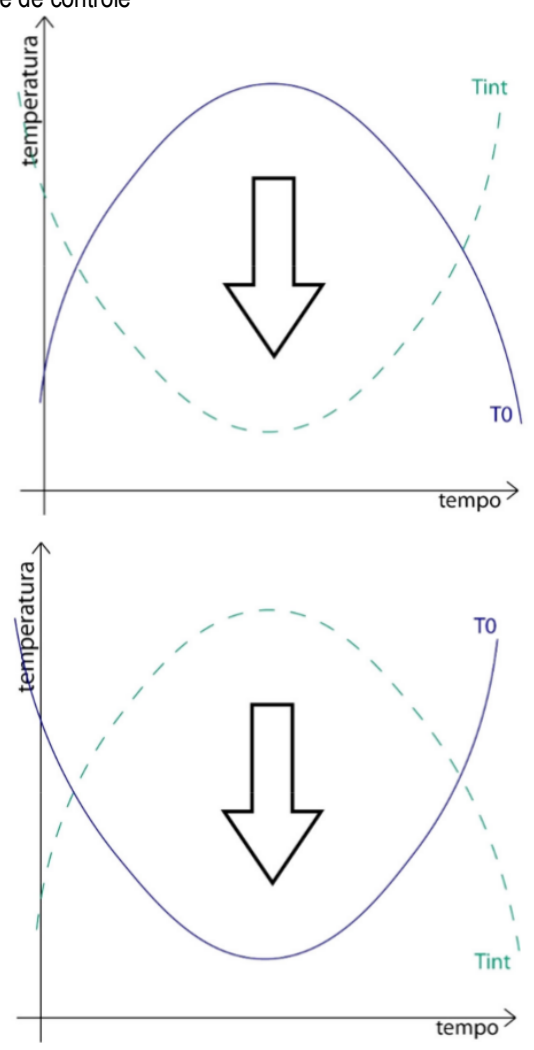

Fonte: (PONS, 2017).

Estratégia 3 - A terceira estimativa de consumo tem como base o último caso apresentado (estratégia 2), porém, não sendo possível utilizar a ventilação inteligente, utiliza-se um agrupamento de ciclos Carnot em espaços de tempo infinitesimais (Figura 9), ou seja, sistemas completamente otimizados (menores valores possíveis de $\Delta \mathrm{T}$ ) para o menor espaço de tempo. Esta proposta de cálculo vem do potencial máximo de eficiência dentro dos limites teóricos. Apesar de ainda não terem sido desenvolvidas tecnologias que permitam tal produtividade em termos de geração de energia térmica, o potencial de fato existe, e o uso de sistemas inteligentes tem um papel importante neste limite de eficiência.

Figura 9 - Estratégia 3 de cálculo do consumo energético para manutenção do conforto térmico no volume de controle

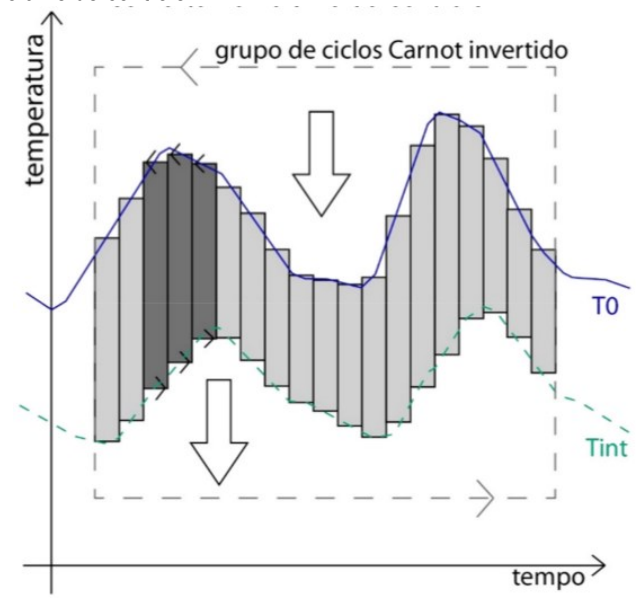

Fonte: (PONS, 2017).

Para finalizar, o algoritmo calcula as exergias anuais (sendo $\mathrm{T}_{0}=298 \mathrm{~K}$ ) por radiação solar para cada caso simulado. Foram quantificadas para cada simulação a fração de exergia solar referente a toda exergia da edificação (exergia solar somada ao consumo energético para ventilação e manutenção da temperatura de conforto).

\section{Resultados e discussão}

O modelo desenvolvido teve os resultados de temperatura hora a hora comparados aos resultados obtidos pelo software EnergyPlus. Utilizando um modelo físico igual e com os mesmos dados de propriedades de materiais em ambos os softwares, a média das diferenças de temperaturas entre as simulações ficou entre $1,16^{\circ} \mathrm{C}$ com desvio padrão de $0,64^{\circ} \mathrm{C}$ e erro padrão de $0,006^{\circ} \mathrm{C}$. Considerando a diferença de complexidade dos métodos de cálculos e fatores como cálculos de coeficientes de convecção internos e externos, a diferença média foi aceitável para a continuidade da pesquisa.

Para cada uma das oito cidades anteriormente citadas foram realizadas as simulações para as 8760 horas de um ano completo. Primeiramente, definiram-se as espessuras ideais para a máxima otimização da entalpia de fusão, para então simular os dois casos definidos na metodologia. 


\section{Zona bioclimática 1 - Curitiba: Simulação sem PCM (caso 1) \& Espessura da camada PCM $=2,5 \mathrm{~cm}$ (caso 2).}

Analisando apenas o cenário referencial e o cenário com PCM na estratégia 1 , houve uma redução de $1,89 \%$ no consumo de energia com utilização do material com mudança de fase. Ao considerar a estratégia 2 , nota-se o impacto da ventilação, sendo que a redução do consumo de energia elétrica com o uso de PCM passou para 9,58\%. Com a última estratégia e o uso do PCM, a redução foi de aproximadamente 40 vezes em relação ao valor do consumo energético de referência (estratégia $1 \mathrm{sem}$ o uso de PCM). Para Curitiba, ficou claro o efeito da ventilação e o impacto da mesma na manutenção da faixa de conforto. $\mathrm{O}$ uso da ventilação apenas quando as temperaturas eram favoráveis permitiu a redução de quase $47 \%$ do consumo de energia. (Gráfico 1)

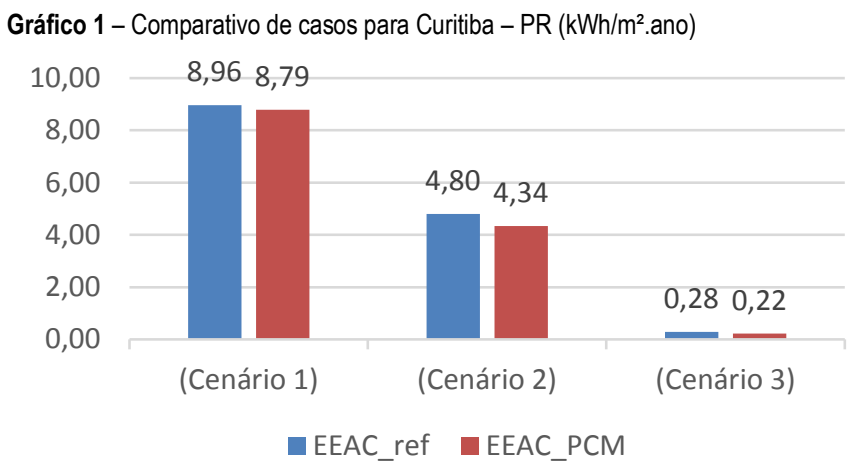

Fonte: (PONS, 2017).

As análises referentes à exergia foram feitas através de uma tabela demonstrando as duas possibilidades (caso 1, sem PCM e caso 2 com material de mudança de fase) para cada cidade estudada e considerando a variação do coeficiente de performance (COP) dos equipamentos de condicionamento de ar considerados nos cálculos. A Tabela 3 apresenta o modelo utilizado para Curitiba. Os valores de exergia anual de radiação solar para Curitiba ficaram em torno de $247,8 \mathrm{kWh} / \mathrm{m}^{2}$.ano. As frações de exergia solar demonstram qual a parcela referente a exergia solar do total de exergia recebida pela edificação, ou seja, para Curitiba, apenas a exergia solar representa de $79 \%$ a $92 \%$ do total.

\section{Zona Bioclimática 2 - Santa Maria: Espessura da camada PCM $=5 \mathrm{~cm}$ (caso 2).}

Para a cidade de Santa Maria, verificou-se uma redução do consumo de energia com a utilização de PCM na carga térmica de aquecimento necessária para manutenção da temperatura de conforto de $72,99 \%$. Porém, para resfriamento a redução é de apenas 3,49\%.

\begin{tabular}{|c|c|c|c|c|c|c|}
\hline & \multirow{4}{*}{$\begin{array}{c}\begin{array}{c}\text { Exergia } \\
\text { Anual } \\
\text { Radiação } \\
\text { Solar }\end{array} \\
\left(\mathrm{kWh} / \mathrm{m}^{2} \text {.ano }\right)\end{array}$} & \multicolumn{5}{|c|}{$\begin{array}{l}\text { Fração de Exergia Recebida (\%) } \\
\qquad \boldsymbol{E} x_{\dot{Q}_{\text {sun }}}\end{array}$} \\
\hline & & \multicolumn{3}{|c|}{$\overline{E x_{\dot{Q}_{\text {sun }}}+\mid \dot{\boldsymbol{W}}_{\text {vent }}}$} & \multicolumn{2}{|c|}{$+\left|\dot{W}_{H P}\right|$} \\
\hline & & \multicolumn{4}{|c|}{ COP } & \\
\hline & & 1 & 2 & 3 & 4 & 5 \\
\hline \multirow{3}{*}{ Referência } & \multirow{3}{*}{247,8434} & 79,04 & 85,12 & 87,36 & 88,53 & 89,24 \\
\hline & & 84,66 & 88,28 & 89,55 & 90,21 & 90,60 \\
\hline & & 91,74 & 91,98 & 92,06 & 92,10 & 92,12 \\
\hline \multirow{3}{*}{$\begin{array}{l}\text { PCM } \\
2,5 \mathrm{~cm}\end{array}$} & \multirow{3}{*}{247,8380} & 79,26 & 85,25 & 87,45 & 88,60 & 89,30 \\
\hline & & 85,33 & 88,64 & 89,80 & 90,39 & 90,75 \\
\hline & & 91,84 & 92,03 & 92,09 & 92,12 & 92,14 \\
\hline
\end{tabular}

Fonte: (PONS, 2017)

O Gráfico 2 apresenta um comparativo dos casos simulados. A estratégia 1 apresenta uma redução de 4,82\% pela utilização de PCM. Quando consideramos a possibilidade de ventilação utilizando a temperatura externa em prol da manutenção do conforto interno, esta redução é de 13,28\%. A estratégia 3 representa uma possibilidade de redução total de $96,11 \%$.

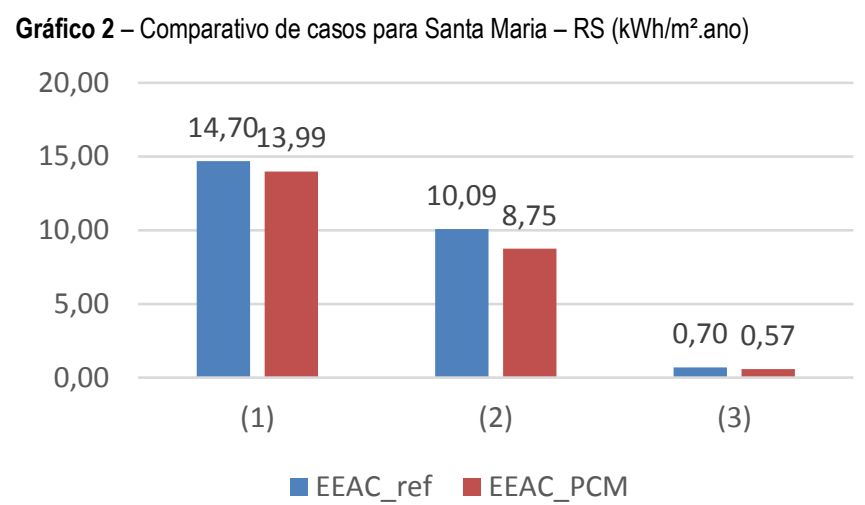

Fonte: (PONS, 2017).

As frações de exergia para a cidade em questão foram valores entre 74 e $92 \%$.

\section{Zona Bioclimática 3 - São Paulo: Espessura da camada PCM $=2,5 \mathrm{~cm}$ (caso 2).}

A utilização de material com mudança de fase na parede externa reduziu a necessidade de aquecimento para 0,27 $\mathrm{kWh} / \mathrm{m}^{2}$.ano de energia térmica, ou seja, $81,48 \%$ de redução, porém o resfriamento não foi tão significativo.

O Gráfico 3 apresenta o comparativo dos consumos energéticos na edificação com e sem material com mudança de fase. Há uma redução mínima de 2,02\% de energia elétrica no primeiro cenário, porém quando utilizada a ventilação como sistema de condicionamento de ar a redução passa a ser de $6,52 \%$. Para a cidade, os resultados mostram 96,98\% de possível redução de energia elétrica com a utilização do PCM juntamente com sistemas mais otimizados de controle de temperatura interna (estratégia 3). 
As frações de exergia tiveram resultados muito próximos aos de Santa Maria, entre $74 \%$ e $92 \%$.

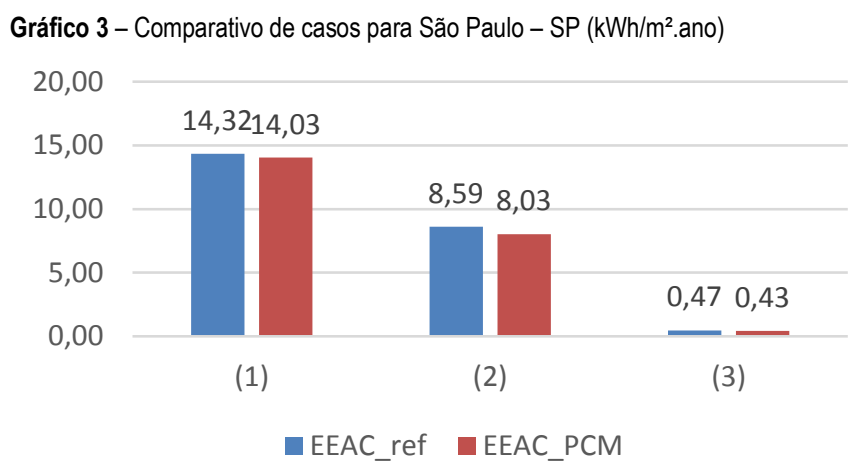

Fonte: (PONS, 2017).

\section{Zona Bioclimática 4 - Brasília: Espessura da camada $\mathrm{PCM}=2,5 \mathrm{~cm}$ (caso 2)}

As simulações para a cidade de Brasília apresentaram um consumo zero de aquecimento e um consumo de energia térmica de 100,36 kWh/m $\mathrm{m}^{2}$ ano, no caso de referência, e $97,10 \mathrm{kWh} / \mathrm{m}^{2}$.ano, com material de mudança de fase. $\mathrm{O}$ consumo elétrico total para o caso de referência reduziu de $20,07 \mathrm{kWh} / \mathrm{m}^{2}$.ano para $19,42 \mathrm{kWh} / \mathrm{m}^{2}$.ano com material de mudança de fase. Para os cenários 2 e 3 de cálculo de consumo de energia elétrica foi necessária uma ventilação forçada de $20,91 \mathrm{kWh} / \mathrm{m}^{2}$.ano.

O Gráfico 4 apresenta um comparativo dos consumos de energia elétrica necessários para os casos estudados para Brasília, considerando os três cenários de cálculos definidos. A utilização de PCM em comparação com o caso de referência desta pesquisa apresenta uma possibilidade de redução do consumo de energia de $3,24 \%$. Considerada a ventilação inteligente como forma de controle de temperatura auxiliando o condicionamento de ar, a redução passa a ser de 5,98\% de consumo elétrico. No último cenário, onde um sistema de condicionamento de ar é otimizado ao limite juntamente com a ventilação inteligente, a redução do consumo elétrico, quando da utilização de material com mudança de fase tem o potencial de chegar a $96,36 \%$, passando de um consumo de $20,07 \mathrm{kWh} / \mathrm{m}^{2}$.ano para $0,73 \mathrm{kWh} / \mathrm{m}^{2}$.ano.

Gráfico 4 - Comparativo de casos para Brasília - DF (kWh/m².ano)

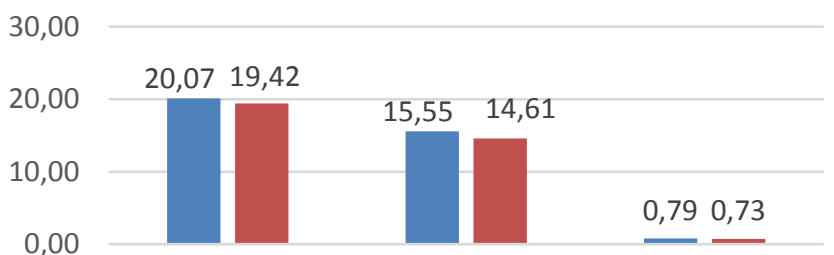

(1)

(2)

(3)
Zona Bioclimática 5 - Vitória da Conquista: Espessura da camada PCM $=2,5 \mathrm{~cm}$ (caso 2)

As simulações verificaram a necessidade de carga térmica para resfriamento de $66,04 \mathrm{kWh} /\left(\mathrm{m}^{2}\right.$.ano $)$ e de 65,62 $\mathrm{kWh} /\left(\mathrm{m}^{2}\right.$.ano) quando utilizado material com mudança de fase. Transformando em consumo elétrico $\mathrm{com} \mathrm{COP}=5$ $\mathrm{W} / \mathrm{W}$, o caso de referência consome $13,21 \mathrm{kWh} /\left(\mathrm{m}^{2}\right.$.ano) de energia elétrica enquanto o caso com material PCM $13,12 \mathrm{kWh} /\left(\mathrm{m}^{2}\right.$.ano $)$, uma redução de $0,68 \%$. No cenário de cálculo 2 a redução do consumo elétrico é de $4,22 \%$. A redução máxima de energia elétrica alcançada é de $96,89 \%$ quando no cenário 3 é utilizado, junto ao PCM como uma das camadas da parede externa da edificação (Gráfico 5).

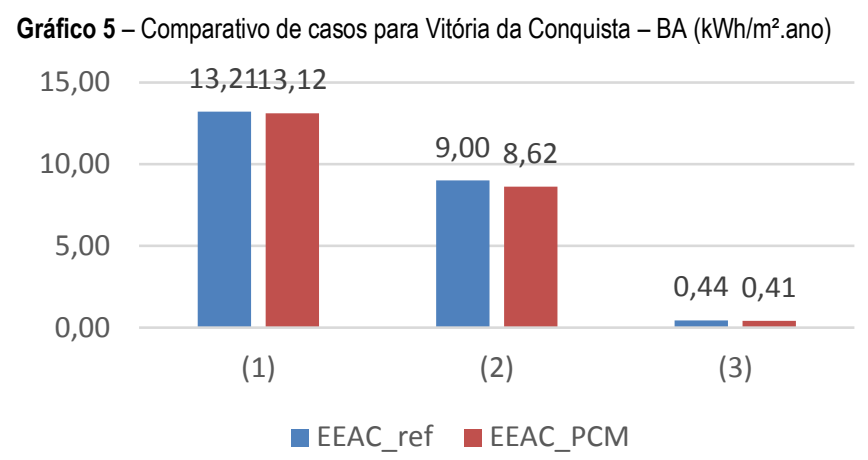

Fonte: (PONS, 2017).

As frações de exergia para Vitória da Conquista foram de aproximadamente $70 \%$ a $90 \%$, com exergia anual de radiação solar 26\%, menor que em Brasília.

\section{Zona Bioclimática 6 - Campo Grande: Espessura da camada PCM $=10 \mathrm{~cm}$ (caso 2)}

Para a cidade de Campo Grande no estado de Mato Grosso do Sul, a espessura mínima calculada do PCM foi de 10 centímetros. Este aumento pode ser entendido quando analisadas as temperaturas hora a hora, em que se percebem as temperaturas internas sempre muito próximas da temperatura de conforto máxima. Tal espessura determinada inviabiliza a utilização do material sob as condições consideradas, porém, para efeito de estudo, apresentam-se os resultados.

O consumo de energia térmica para aquecimento, existente no caso de referência, é zerado quando utilizado material com mudança de fase no modelo. Já para resfriamento, foi calculado $131,33 \mathrm{kWh} / \mathrm{m}^{2}$. ano de energia térmica, quando não utilizado material com mudança de fase, e 117,85 $\mathrm{kWh} / \mathrm{m}^{2}$.ano, quando o material foi implantado na envoltória da edificação, causando uma redução de $10,26 \%$ no total de energia térmica. Esta redução passa a $13,05 \%$ quando considerado o segundo cenário de cálculo (Gráfico 6). 
Gráfico 6 - Comparativo de casos para Campo Grande - MS (kWh/m².ano)

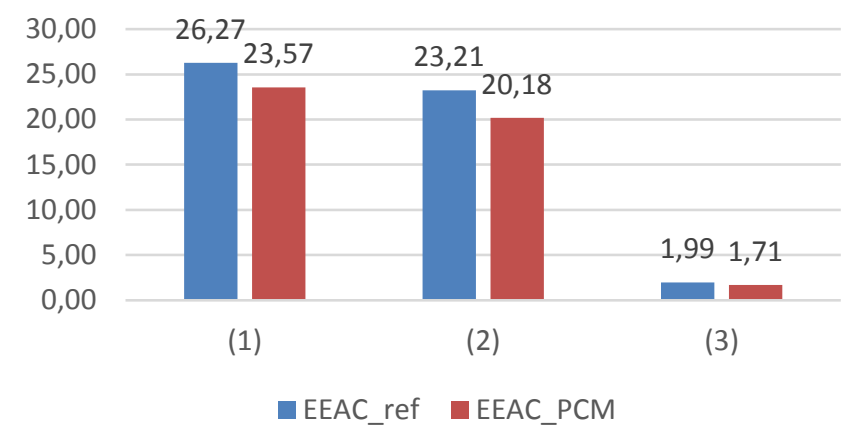

Fonte: (PONS, 2017).

Pela simulação, obteve-se uma quantidade de exergia de $291,7614 \mathrm{kWh} / \mathrm{m}^{2}$.ano, gerando frações de exergia que variam de $65,71 \%$ a $92,80 \%$, COP de 1 e 5 W/W respectivamente.

\section{Zona Bioclimática 7 - Cuiabá: Espessura da camada $\mathrm{PCM}=35 \mathrm{~cm}$}

A próxima cidade simulada foi Cuiabá, no estado do Mato Grosso. O início das simulações, assim como nas outras cidades, se deu pela definição da espessura mínima do material com mudança de fase para utilização do total potencial de armazenamento de energia durante a liquefação do material. Esta etapa gerou um resultado de $35 \mathrm{~cm}$ de espessura que, se comparado com a parede de referência $(15 \mathrm{~cm})$ significa mais do que o dobro de espessura apenas para o PCM.

Para a cidade de Cuiabá, foi verificada a necessidade de $33,79 \mathrm{kWh} /\left(\mathrm{m}^{2} \cdot\right.$ ano $)$ de energia elétrica para o condicionamento de ar no caso de referência, enquanto com o uso de PCM este valor é de $25,77 \mathrm{kWh} /\left(\mathrm{m}^{2} \cdot\right.$ ano $)$ (Gráfico 7). Esta redução representa 23,73\% a menos de consumo energético. Porém, o fato de serem necessários $35 \mathrm{~cm}$ de material com mudança de fase torna esta alternativa inviável, haja visto o custo e o aumento considerável na espessura da envoltória da edificação.

Gráfico 7 - Comparativo de casos para Cuiabá - $M G\left(\mathrm{kWh} / \mathrm{m}^{2}\right.$.ano)

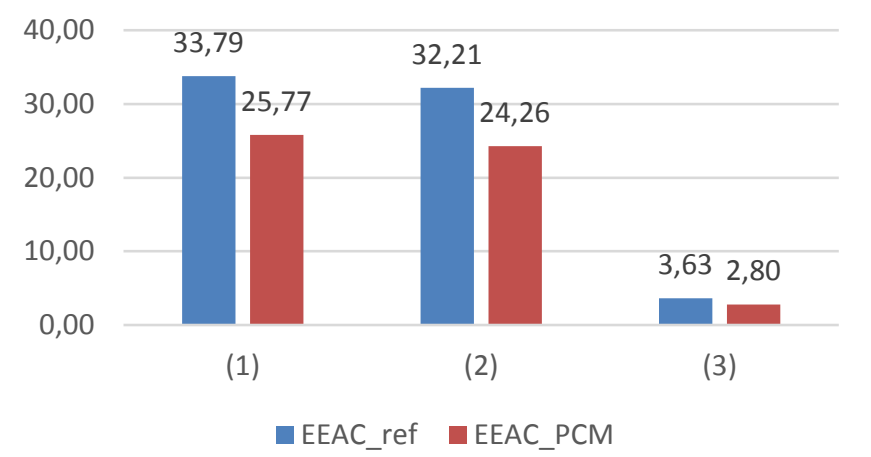

Fonte: (PONS, 2017).

\section{Zona Bioclimática 8 - Rio de Janeiro: Espessura da camada $\mathrm{PCM}=10 \mathrm{~cm}$}

A última cidade a ser simulada, representando a Zona Bioclimática 8 do Brasil, foi o Rio de Janeiro. Assim como em Campo Grande, foram necessários $10 \mathrm{~cm}$ de material com mudança de fase na parede externa para que o potencial máximo de armazenamento de energia fosse aproveitado. Assim como nos casos de Campo Grande e Cuiabá, a espessura necessária inviabiliza a utilização, porém seguem os dados obtidos.

As simulações de fato mostraram que não há necessidade de aquecimento para nenhum dos dois casos simulados em qualquer época do ano. Porém, para a manutenção do conforto térmico interno são necessários 123,12 $\mathrm{kWh} /\left(\mathrm{m}^{2} \cdot \mathrm{ano}\right)$ de carga térmica para resfriamento no caso de referência e $110,35 \mathrm{kWh} /\left(\mathrm{m}^{2} \cdot\right.$ ano $)$ quando implantado o PCM na parede externa. Estes valores se revertem em $24,62 \mathrm{kWh} /\left(\mathrm{m}^{2} \cdot \mathrm{ano}\right)$ e $22,07 \mathrm{kWh} /\left(\mathrm{m}^{2} \cdot\right.$ ano $)$ de energia elétrica.

Ficam claras as reduções quando analisado o Gráfico 8 . Apenas no cenário 1 é possível verificar uma redução de $10,37 \%$ no consumo de energia elétrica. Quando implantada a ventilação inteligente (estratégia 2) há um potencial de redução de 13,16\%. Quando analisado o cenário 3 , a redução, apenas pela utilização do material com mudança de fase, é de $14,40 \%$. Juntando o potencial máximo, é de $96,58 \%$ de redução do consumo energético, considerando a utilização de PCM, ventilação inteligente e um sistema de condicionamento de ar otimizado.

Gráfico 8 - Comparativo de casos para Rio de Janeiro - RJ (kWh/m².ano)

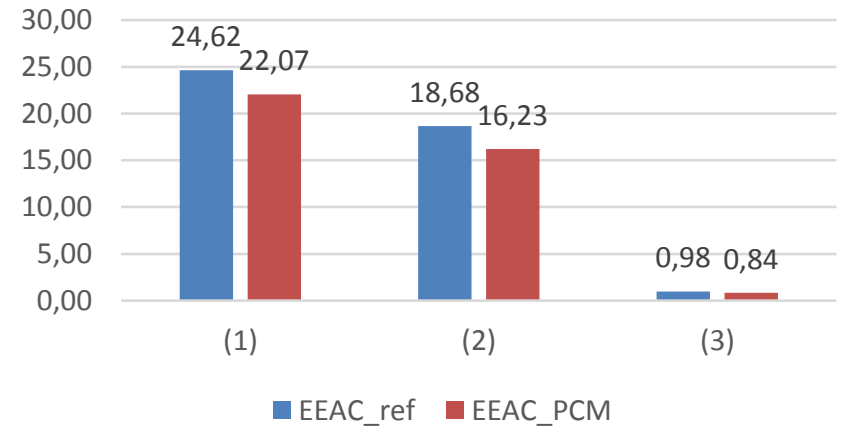

Fonte: (PONS, 2017).

\section{Resumo dos Resultados}

Para visualização do impacto da utilização do material PCM na vedação externa em todas as cidades, foram criados gráficos para cada um dos três cenários, sendo eles, cenário 1 (Gráfico 9) sistema com condicionamento de ar sem otimização, cenário 2 (Gráfico 10) ventilação como auxílio ao condicionamento de ar e cenário 3 (Gráfico 11) sistema de condicionamento de ar otimizado e ventilação quando possível. 


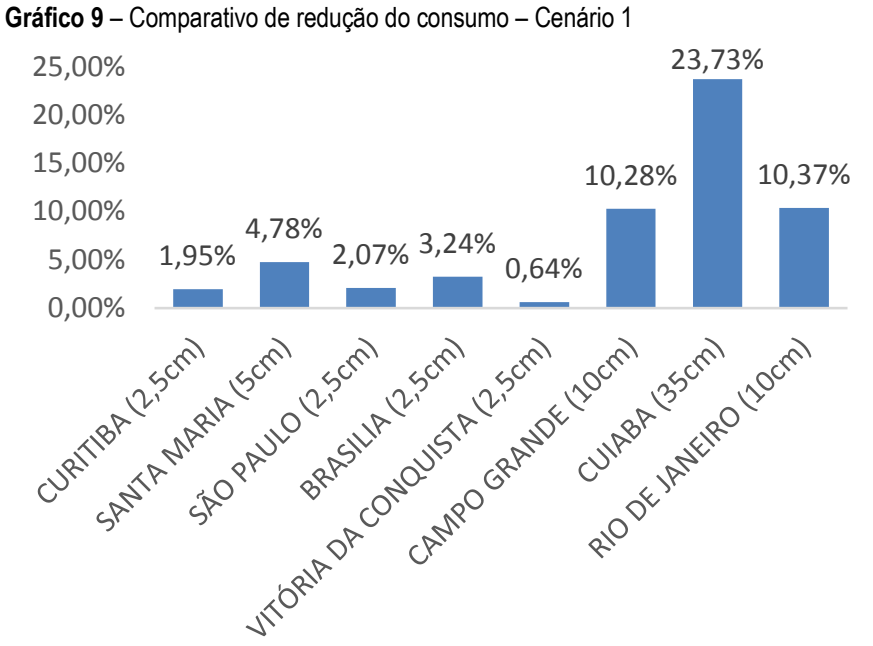

Fonte: (PONS, 2017).

Gráfico 10 - Comparativo de redução do consumo - Cenário 2

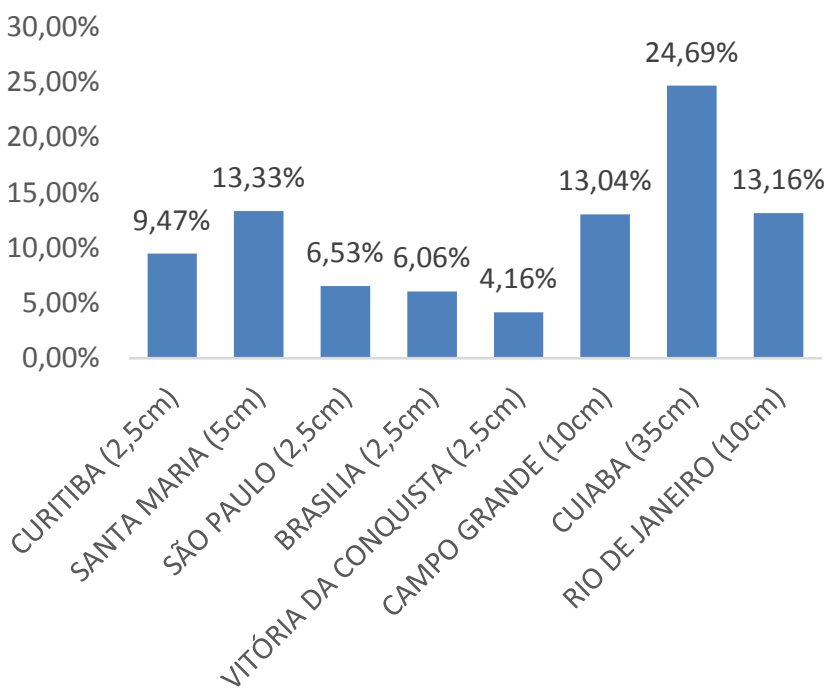

Fonte: (PONS, 2017).

Nota-se claramente que Cuiabá apresenta a maior redução do consumo de energia elétrica, porém deve-se ficar claro que a espessura mínima para que não houvesse a total liquefação do PCM foi de $35 \mathrm{~cm}$, o que é uma quantidade de material inviável, haja vista que lidamos nesta pesquisa com placas de $0,5 \mathrm{~cm}$ de espessura.

No cenário 2, a utilização de PCM unida à ventilação inteligente (estratégia 2) possui maior possibilidade de redução da energia necessária para manutenção da faixa de temperatura de conforto térmico. Todas as cidades, exceto Cuiabá, apresentaram uma melhora nos resultados com a ventilação, auxiliando no condicionamento de ar. Esta estratégia de controle de temperatura permitiu uma redução extra de $8 \%$, aproximadamente, para a cidade de Santa Maria, no estado do Rio Grande do Sul.
Gráfico 11 - Comparativo de redução do consumo - Cenário 3

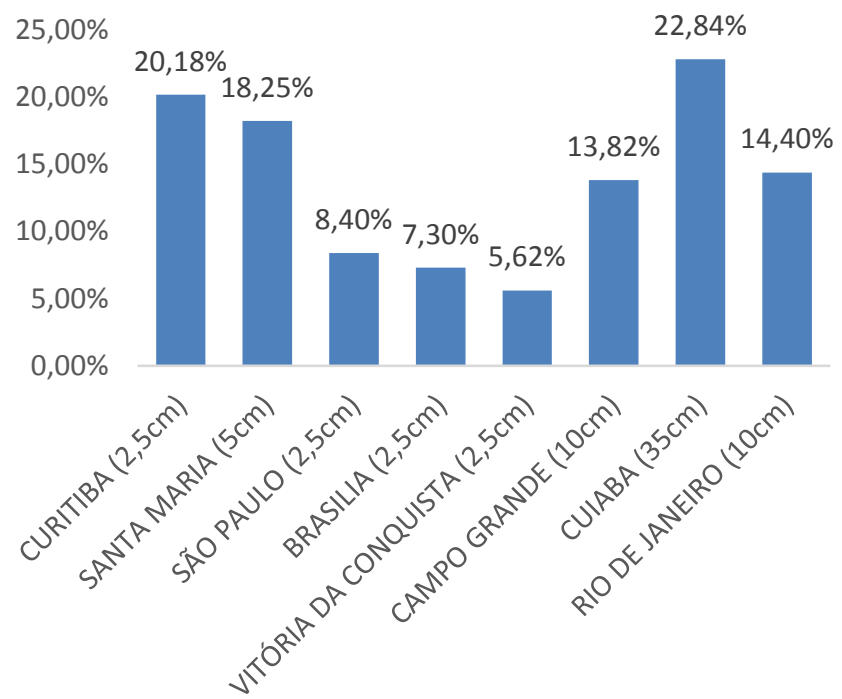

Fonte: (PONS, 2017).

No último cenário, a utilização de um sistema de condicionamento de ar otimizado em seu limite, possibilita o maior potencial do material com mudança de fase. As melhorias se deram principalmente nas cidades mais frias simuladas, Curitiba e Santa Maria, com espessuras de PCM de $2,5 \mathrm{~cm}$ e $5 \mathrm{~cm}$ respectivamente, onde as reduções do consumo de energia pelo impacto do uso do material estudado ficaram entre $18,25 \%$ e $20,18 \%$.

$\mathrm{O}$ potencial total de redução do consumo de energia elétrica simulado demonstra, na teoria, o impacto do uso de sistemas de condicionamento de ar mais otimizados juntamente com materiais de mudança de fase. O menor potencial de redução do consumo de energia elétrica foi de $91,71 \%$ para Cuiabá e o maior potencial foi de $97,51 \%$ para Curitiba.

\section{Conclusão}

Os resultados deste trabalho comprovam que os materiais com mudança de fase podem sim, em certas condições climáticas, como as zonas bioclimáticas brasileiras $1,2,3$, 4 e 5 , reduzir o consumo de energia na manutenção do conforto térmico em ambientes construídos.

Considerando a estratégia 1 de condicionamento de ar, utilização de bomba de calor, a redução chegou a 4,28\% para a cidade de Santa Maria e aproximadamente $10 \%$ para Campo Grande e Rio de Janeiro com o uso do material com mudança fase. Adicionada a possibilidade de ventilação (estratégia 2) quando a diferença entre temperatura interna e externa é favorável, os resultados foram ainda melhores. Na cidade de Curitiba a utilização de PCM contribuiu para uma redução de $9,47 \%$, enquanto em Santa Maria o potencial de redução do consumo energético passou de $13 \%$. Valores próximos foram encontrados também para Rio de Janeiro e Campo Grande. 
Quando considerado o cenário 3, onde há a utilização de um sistema de condicionamento de ar otimizado, as reduções do consumo foram mais expressivas. A cidade de Curitiba obteve os melhores resultados, com $20 \%$ de possível economia.

O emprego de sistemas inteligentes, que possibilitem a troca de calor com o exterior juntamente com um condicionamento de ar otimizado ao seu limite (neste trabalho chamado de estratégia 3), obtiveram-se valores significativos quanto à possibilidade de redução do consumo atual de energia. Os valores chegaram a mais de $90 \%$ de redução do consumo total de energia elétrica (sem o uso de PCM) para manutenção do conforto térmico interno em relação ao valor de referência. Existe, sem dúvida, um claro potencial de redução do consumo energético, como indicam os resultados deste estudo, mas cujo aproveitamento depende do desenvolvimento tecnológico.

Porém, considerando-se as oito zonas bioclimáticas definidas de acordo com a norma brasileira NBR 15.220 (ABNT, 2005), entende-se que não se pode chegar a uma solução única sobre o impacto da utilização de materiais com mudança de fase na redução do consumo de energia para manutenção do conforto térmico para todas as zonas. A variação das propriedades do material de mudança de fase, entalpia de fusão e temperatura de fusão, como percorrido na bibliografia, influenciam no impacto sobre o modelo físico estudado.
Para as cidades de Cuiabá, Campo Grande e Rio de Janeiro, o método levou a camadas de material com mudança de fase com mais de $10 \mathrm{~cm}$ de espessura. Novos estudos podem ser realizados utilizando PCMs com temperaturas de fusão superiores para buscar melhores resultados para estas cidades.

Resultados adicionais apresentados neste trabalho são as frações de exergia solar em relação a exergia total recebida pelo ambiente simulado. Em todos os casos, essas frações tiveram valores de no mínimo $65,71 \%$ e no máximo $92,95 \%$, ou seja, a exergia solar tem o potencial de geração de energia suficiente para manter a temperatura interna na faixa de conforto. É clara a necessidade de avanço tecnológico para que esta transformação de exergia em energia elétrica aconteça sem tanta perda energética, porém este trabalho se limitou a levantar estes dados de maneira a melhor entender a representatividade dos mesmos. A exergia solar se não utilizada é uma energia desperdiçada, ou seja, trata-se de um gasto de energia. Mesmo em edificações onde não há consumo de energia vinda da concessionária, há sim um gasto energético pela recepção de exergia solar. E esse gasto é extremamente significativo como os números demonstram nesta pesquisa. Essa discussão vem de encontro ao conceito de "zero energy buildings", pois a construção, a menos que não esteja sob o efeito de luz solar ou ventos, receberá exergia destes fenômenos.

\section{Notas}

(1) BASF. BASF MICRONAL. Disponível em: <https://www.basf.com/images/corp/news-media/science-around-us/wax-inthe-wall-for-a-pleasant-indoor-climate/micronal_small_4-3.jpg>. Acesso em: 15 set 2016.

\section{Referências}

ABHAT, A. Low temperature latent heat thermal energy storage: Heat storage materials. Solar Energy, v. 30, n. 4, p. 313-332, 1983. ISSN: 0038-092X. https://doi.org/10.1016/0038-092X(83)90186-X

ABNT - ASSOCIAÇÃO BRASILEIRA DE NORMAS TÉCNICAS. NBR 15.220: Desempenho térmico de edificações. Rio de Janeiro, 2005.

ABNT - ASSOCIAÇÃO BRASILEIRA DE NORMAS TÉCNICAS. NBR 15.575: Edificações habitacionais - Desempenho. Rio de Janeiro, 2013.

ABNT - ASSOCIAÇÃO BRASILEIRA DE NORMAS TÉCNICAS. NBR 16.401: Instalações de ar-condicionado - Sistemas centrais e unitários. Rio de Janeiro, 2008.

ASHRAE - American Society of Heating, Refrigerating and Air-Conditioning Engineers. Ashrae Standard 55 - Thermal environmental conditions for human occupancy. Atlanta, 2013.

BODACH, S.; HAMHABER, J. Energy efficiency in social housing: Opportunities and barriers from a case study in Brazil. Energy Policy, v. 38, n. 12, p. 7898-7910, 2010. ISSN: 0301-4215. https://doi.org/10.1016/j.enpol.2010.09.009.

BRASIL. Ministério das Minas e Energia. Balanço Energético Nacional: ano base 2016 - Final. Brasília, 2016. 
CABEZA, L. F. et al. Use of microencapsulated PCM in concrete walls for energy savings. Energy and Buildings, v. 39, n. 2, p. 113-119, fev. 2007. ISSN: 0378-7788. https://doi.org/10.1016/j.enbuild.2006.03.030.

DE GRACIA, A. et al. A simple model to predict the thermal performance of a ventilated facade with phase change materials. Energy and Buildings, v. 93, p. 137-142, 2015. ISSN: 0378-7788. https://doi.org/10.1016/j.enbuild.2015.01.069.

ELETROBRAS. Pesquisa de posse de equipamentos e hábitos de uso, ano base 2005: classe Residencial Relatório Brasil Sumário Executivo. Rio de Janeiro: ELETROBRAS; PROCEL, 2009. 187 p. (Avaliação do Mercado de Eficiencia Energética no Brasil).

FIORITO, F. Phase-change Materials for Indoor Comfort Improvement in Lightweight Buildings. A Parametric Analysis for Australian Climates. Energy Procedia, v. 57, n. 0, p. 2014-2022, 2014. ISSN: 1876-6102.

https://doi.org/10.1016/j.egypro.2014.10.066.

HALFORD, C. K.; BOEHM, R. F. Modeling of phase change material peak load shifting. Energy and Buildings, v. 39, p. 298305, 2007. ISSN: 0378-7788. https://doi.org/10.1016/j.enbuild.2006.07.005.

HUANG, M. J.; EAMES, P. C.; NORTON, B. Thermal regulation of building-integrated photovoltaics using phase change materials. International Journal of Heat and Mass Transfer, v. 47, n. 12-13, p. 2715-2733, 2004. ISSN: 0017-9310. https://doi.org/10.1016/j.ijheatmasstransfer.2003.11.015.

IZQUIERDO-BARRIENTOS, M. A. et al. A numerical study of external building walls containing phase change materials (PCM). Applied Thermal Engineering, v. 47, p. 73-85, dez. 2012. ISSN: 1359-4311. https://doi.org/10.1016/j.applthermaleng.2012.02.038.

JEONG, S. G. et al. Improvement of the thermal properties of Bio-based PCM using exfoliated graphite nanoplatelets. Solar Energy Materials and Solar Cells, v. 117, p. 87-92, 2013. ISSN: 0927-0248. https://doi.org/10.1016/j.solmat.2013.05.038

KALNÆS, S. E.; JELLE, B. P. Phase Change Materials for Building Applications: A State-of-the-Art Review and Future Research Opportunities. Energy and Buildings, v. 94, n. 7491, p. 150-176, 2015. ISSN: 0378-7788.

https://doi.org/10.1016/j.enbuild.2015.02.023.

KONG, X. et al. Experimental research on the use of phase change materials in perforated brick rooms for cooling storage. Energy and Buildings, v. 62, p. 597-604, 2013. ISSN: 0378-7788. https://doi.org/10.1016/j.enbuild.2013.03.048.

KOSNY, J. et al. Dynamic thermal performance analysis of fiber insulations containing bio-based phase change materials (PCMs). Energy and Buildings, v. 52, p. 122-131, 2012. ISSN: 0378-7788. https://doi.org/10.1016/j.enbuild.2012.05.021.

LEE, K. O. et al. Assessing the integration of a thin phase change material (PCM) layer in a residential building wall for heat transfer reduction and management. Applied Energy, v. 137, p. 699-706, 2015. ISSN: 0306-2619.

https://doi.org/10.1016/j.apenergy.2014.09.003.

MANDILARAS, I. et al. Experimental thermal characterization of a Mediterranean residential building with PCM gypsum board walls. Building and Environment, v. 61, p. 93-103, 2013. ISSN: 0360-1323. https://doi.org/10.1016/j.buildenv.2012.12.007.

PEREIRA, C. D.; LAMBERTS, R.; GHISI, E. Nota técnica referente aos níveis mínimos de eficiência energética de condicionadores de ar no Brasil. 2013.

PONS, Vinícius. Estudo do potencial dos materiais com mudança de fase para redução do consumo de energia na manutenção do conforto térmico no ambiente construído. 2017. 113f. Dissertação (Mestrado em Engenharia de Construção Civil) - Programa de Pós-graduação em Engenharia da Construção Civil, Universidade Federal do Paraná, Curitiba, 2017.

ROBSON, C. Real World Research: a resource for social scientists and practioner-researchers. 2.ed. Oxford: Blackwell, 2002.

RORIZ, M. Arquivos climáticos de municípios brasileiros. ANTAC - Associação Nacional de Tecnologia no Ambiente Construído. São Carlos - SP. Janeiro de 2012a. 
SAJJADIAN, S. M.; LEWIS, J.; SHARPLES, S. The potential of phase change materials to reduce domestic cooling energy loads for current and future UK climates. Energy and Buildings, v. 93, p. 83-89, 2015. ISSN: 0378-7788. https://doi.org/10.1016/j.enbuild.2015.02.029.

SILVA, T. et al. Experimental testing and numerical modelling of masonry wall solution with PCM incorporation: A passive construction solution. Energy and Buildings, v. 49, p. 235-245, 2012. ISSN: 0378-7788.

https://doi.org/10.1016/j.enbuild.2012.02.010.

SOARES, N. et al. Multi-dimensional optimization of the incorporation of PCM-drywalls in lightweight steel-framed residential buildings in different climates. Energy and Buildings, v. 70, p. 411-421, 2014. ISSN: 0378-7788.

https://doi.org/10.1016/j.enbuild.2013.11.072.

STANESCU, G.; SCHMID, A. L. Thermodynamic Approach On The Condensation Risk In Built Environment. HEFAT2014, n. Julho, 2014. Disponível em: http://hdl.handle.net/2263/44753. Acesso em: 15 dez. 2017.

U.S. DEPARTMENT OF ENERGY. EnergyPlus. Energy Simulation Software, 2016. Disponível em: $<$ http://apps1.eere.energy.gov/buildings/energyplus/>

WANG, Q.; ZHAO, C. Y. Parametric investigations of using a PCM curtain for energy efficient buildings. Energy and Buildings, v. 94, p. 33-42, 2015. ISSN: 0378-7788. https://doi.org/10.1016/j.enbuild.2015.02.024.

\section{${ }^{1}$ Vinícius Pons}

Arquiteto e Urbanista. Bacharel. Endereço postal: Rua Carneiro Lobo, 444 apto 101, Curitiba, PR, Brasil, CEP: 80240-240

${ }^{2}$ George Stanescu

Engenheiro Mecânico. Doutor. Endereço postal: Caixa postal 19011, Curitiba, PR, Brasil, CEP: 81531-990 